\title{
Inhibition of RANKL-stimulated osteoclast differentiation by Schisandra chinensis through down-regulation of NFATc1 and c-fos expression
}

\author{
Eun-Jung Kim ${ }^{1}$, Haesu Lee ${ }^{2}$, Mi Hye Kim² and Woong Mo Yang ${ }^{2 *}$
}

\begin{abstract}
Background: Schisandra chinenesis (SC) has been reported to have ameliorative effect on osteoporosis. However, the mechanisms underlying the anti-osteoporosis activity of SC have not been clearly elucidated. In the present study, we determined the effects of SC on The receptor activator of NF-kB ligand (RANKL)-induced osteoclastogenesis and its potential mechanism.

Methods: Raw 264.7 cells were treated with $0.6,6$ and $60 \mu \mathrm{g} / \mathrm{mL} \mathrm{SC}$ in the presence of $100 \mathrm{ng} / \mathrm{mL}$ RANKL for 7 days. RANKL-induced osteoclast formation was analyzed by tartrate resistant acid phosphatase (TRAP) staining. The osteoclast differentiation-related factors were confirmed along with TNF-a.

Results: SC inhibits the RANKL-induced osteoclast differentiation in dose-dependent manner within non-toxic concentrations. The supernatant concentrations of TNF-a were significantly decreased by SC treatment. In addition, osteoclastogenesis-related factors, TRAP6 and NF-KB, were markedly decreased by SC in RANKL-induced osteoclasts. Mechanistically, SC reduced the RANKL-triggered NFATc1 and c-fos expressions.

Conclusions: Taken together, our data suggest that SC can modulate bone metabolism by suppressing RANKLinduced osteoclast differentiation.
\end{abstract}

Keywords: Schisandra chinensis, Osteoclastogenesis, RANKL, NFATc1, C-fos

\section{Background}

Osteoclast, the bone-resorbing multinucleated giant cells, developed from the monocyte-macrophage lineage cells [1]. Excessive osteoclast activity leads to an imbalance between bone resorption and formation, which is frequently observed in various osteopenic diseases such as osteoporosis [2], skeletal metastases [3], periodontitis [4], Paget's disease [5] and rheumatoid arthritis [6].

The receptor activator of nuclear factor-kappa B ligand (RANKL) belongs to the tumor necrosis factor (TNF) receptor-ligand family, and is directly involved in the differentiation of osteoclasts through its receptor,

\footnotetext{
* Correspondence: wmyang@khu.ac.kr

${ }^{2}$ Department of Convergence Korean Medical Science, College of Korean Medicine, Kyung Hee University, 26 Kyungheedae-ro, Dongdaemun-gu, Seoul 02447, Republic of Korea

Full list of author information is available at the end of the article
}

RANK [7]. RANKL-induced stimulation of RANK on hematopoietic precursor cells leads to the recruitment of TNF receptor-associated factors (TRAF) and the following activation of several downstream signaling pathways such as nuclear factor-kappa B (NF-kB), mitogen-activated protein kinase (MAPKs), c-fos and nuclear factor of activated T cells (NFATc1), ultimately resulting in generating mature osteoclasts [8-11]. Therefore, the investigation of targeted modulation of RANKL signaling pathways to regulate the differentiation of osteoclasts may have significant therapeutic implications for the treatment of bone erosive diseases such as osteoporosis, periodontitis and osteoarthritis [12].

The fruit of Schisandra chinensis (Turcz.) Baill. (Schisandraceae) has been used for the treatment of rheumatoidal and degenerative arthritis in traditional Korean medicines [13]. S. chinensis, also known as Omija in Korea, has been

(c) The Author(s). 2018 Open Access This article is distributed under the terms of the Creative Commons Attribution 4.0 International License (http://creativecommons.org/licenses/by/4.0/), which permits unrestricted use, distribution, and reproduction in any medium, provided you give appropriate credit to the original author(s) and the source, provide a link to the Creative Commons license, and indicate if changes were made. The Creative Commons Public Domain Dedication waiver (http://creativecommons.org/publicdomain/zero/1.0/) applies to the data made available in this article, unless otherwise stated. 
widely harvested in East Asia including Korea, China, Japan and Russia [14]. S. chinensis contains several lignans, mainly schizandrin and gomisin $\mathrm{A}$, which have been shown to possess a stimulating activity of osteoblastic proliferation in vitro $[15,16]$. Recently, S. chinensis has been reported to exhibit an ameliorative effects against osteoporosis through the activation of estrogen receptors [17]. Several individual pathways including NF- $\mathrm{kB}$ and MAPKs pathways have been suggested for regulation of lipopolysaccharide-induced inflammation by treatment of S. chinensis or its lignans [18-20]. Interestingly, Schisantherin A, a main constituent of Schisandra sphenanthera Rehder \& E. H. Wilson (Schisandraceae), not a predominant constituent of $S$. chinensis, is reported to suppress the osteoclast formation in vitro [21, 22].
However, the effects of $S$. chinensis on the differentiation of osteoclasts and their underlying mechanisms have not been fully clarified yet.

In the present study, we evaluated the effects of $S$. chinensis on RANKL-induced osteoclastogenesis and investigated the potential mechanisms of inhibiting osteoclasts differentiation by interfering with RANKL signaling pathways.

\section{Methods}

Preparation of SC

S. chinensis was purchased from OmizaValley Inc. (Mungyeong-si, Korea). The crude extract of $S$. chinensis was prepared by refluxing. $400 \mathrm{~g}$ of $S$. chinensis was boiled with distilled water at $100{ }^{\circ} \mathrm{C}$ for $2 \mathrm{~h}$ and filtered through

A

RANKL

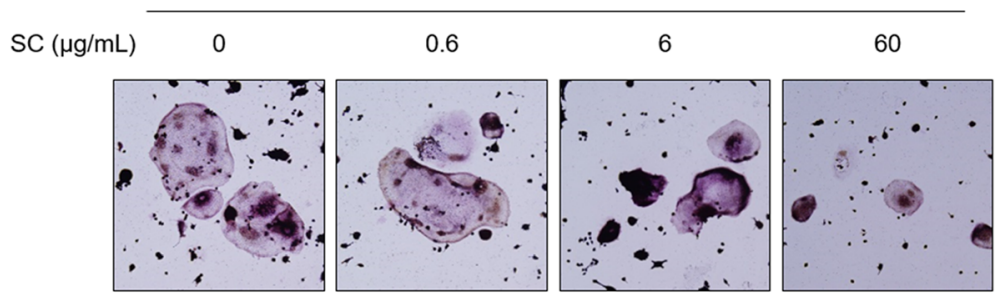

B

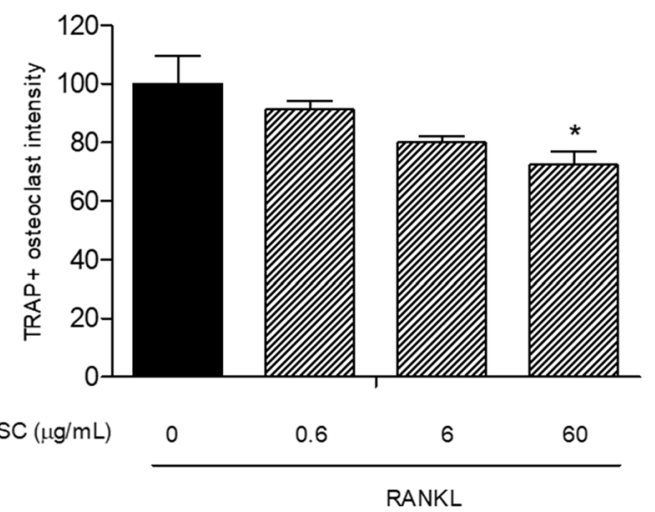

C

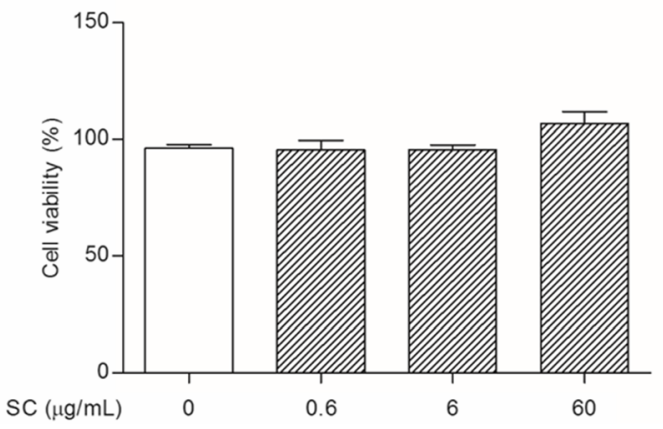

Fig. 1 The effects of SC on osteoclast differentiation in RANKL-stimulated RAW 264.7 cells. a RAW 264.7 cells $\left(8 \times 10^{4}\right.$ per well) were incubated with $100 \mathrm{ng} / \mathrm{mL}$ RANKL or both RANKL and SC $(0.6,6$ and $60 \mu \mathrm{g} / \mathrm{mL})$ for 7 days and then stained for TRAP. Magnification, 100x original. b TRAP activity was measured using an ELISA reader (optical density, $410 \mathrm{~nm}$ ). Data are represented as the means \pm S.E.M. of three independent experiments. ${ }^{*} p<0.05$ compared with only RANKL-treated cells. c Cell viability was confirmed by MTT assay 
$185 \mathrm{~mm}$ filter paper. The extract was lyophilized and called SC. The final yield was $35 \%$. A voucher specimen (SC-W100) of plant was deposited in the college of Korean Medicine, Kyung Hee University, Seoul, Korea. The quality evaluation of SC was determined by high-performance liquid chromatography with evaporative light scattering detector (HPLC-ELSD; HPLC Agilent 1100 series). Shizandrin was used as a marker of SC. Thirty mg SC was dissolved in $1 \mathrm{~mL} \mathrm{30 \%} \mathrm{ethanol} \mathrm{and}$ sonicated for $30 \mathrm{~min}$. Following filtering through a $0.45 \mu \mathrm{m}$ filter membrane, $10 \mu \mathrm{L}$ of 2 fold diluted aliquot was injected to HPLC-ELSD system equipped with a Atlantis HILIC silica $(4.6 \times 150 \mathrm{~mm}, 5 \mu \mathrm{m}, 100 \AA)$. The correlation coefficient (R2) reached 0.9999 . The concentration of schizandrin in SC was $164.372 \mu \mathrm{g} / \mathrm{mL}(1.820 \%)$ shown in Additional file 1.

\section{Osteoclast formation}

The murine RAW 264.7 cells were seeded at a density of $8 \times 10^{4}$ cells per well in 6 well plates. The growing medium is $\alpha$-Minimum Essential Medium Eagle ( $\alpha$-MEM) supplemented with $10 \%$ heat inactivated fetal bovine serum (FBS) and 100 units $/ \mathrm{mL}$ penicillin. To generate osteoclasts, all cells without non-treated cells were incubated with RANKL. Then RANKL-induced cells were either left untreated or treated with various concentrations of SC $0.6,6$ or $60 \mu \mathrm{g} / \mathrm{mL}$ for 7 days. Non-treated cells were not treated RANKL and SC as normal control. The media was replaced after 3 days. Tartrate resistant acid phosphatase (TRAP) staining was performed in 7 days using a commercial kit (Sigma, MO, USA). Cells were treated with TRAP staining solution including $1 \%$ naphthol AS-BI phosphate, 2\% diazotized Fast Garnet GBC solution in sodium nitrite, $4 \%$ acetate solution and $2 \%$ tartrate solution for $30 \mathrm{~min}$. TRAP-stained cells were counterstained by hematoxylin and monitored under a light microscope using the Leica Application Suite (LAS; Leica Microsystems, Buffalo Grove, IL, USA). Osteoclasts were defined as TRAP-positive multinucleated cells $(>3$ nuclei/cell). To quantify the TRAP intensity, each well was added $400 \mu \mathrm{L}$ of citrate solution including sodium tartrate and p-nitrophenylphosphate. After $1 \mathrm{~h}$, supernatant was collected, $400 \mu \mathrm{L}$ of $0.1 \mathrm{~N}$ sodium hydroxide was added and measured at $410 \mathrm{~nm}$ using a microplate reading instrument. The experiments were carried out 3 times in triplicate measurements. The cytotoxicity of Raw 264.7 cells was confirmed by 3-(4,5-Dimethylthiazol-2-yl)-2,5-Diphenyltetrazolium Bromide (MTT) assay. Raw 264.7 cells were treated in the presence of $0.6,6$ and $60 \mu \mathrm{g} / \mathrm{mL} \mathrm{SC}$ for $24 \mathrm{~h} .2 \mathrm{mg} / \mathrm{mL}$ MTT solution was added into cells and color density at $570 \mathrm{~nm}$ absorbance was detected by a microplate reading instrument.

\section{Enzyme-linked immunosorbent assay (ELISA)}

The supernatants derived from osteoclasts were collected at 7 days after RANKL and SC treatment. The concentration of TNF- $\alpha$ was quantified using TNF- $\alpha$ ELISA kit (BD Bioscience, San Jose, CA, USA) according to the manufacturer's protocol. Color development at $450 \mathrm{~nm}$ was measured.

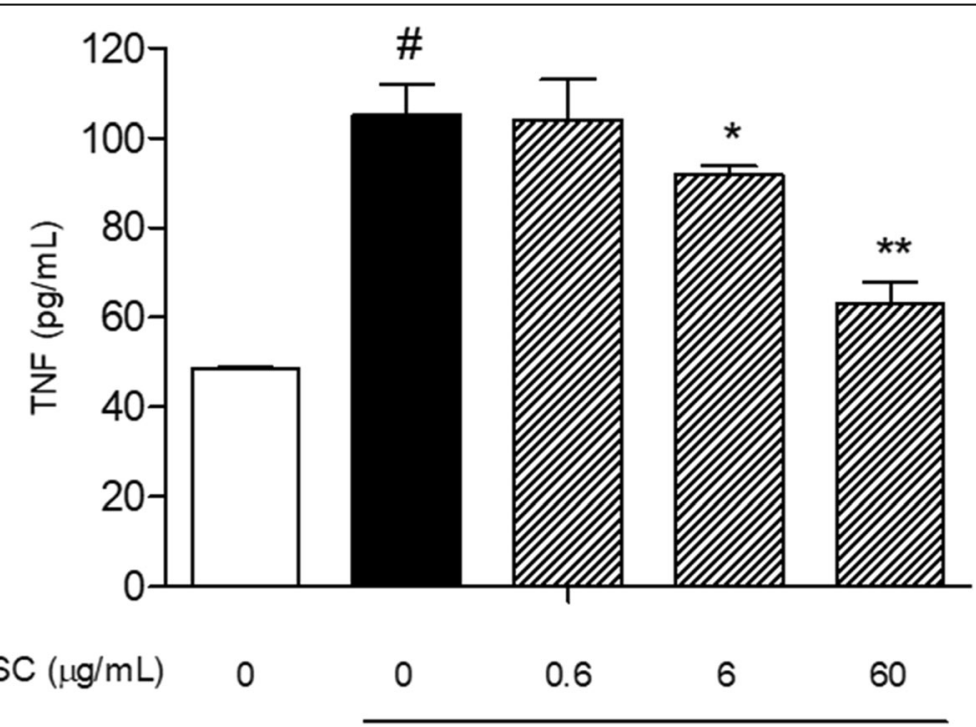

RANKL

Fig. 2 The effect of SC on TNF-a secretion in RANKL-stimulated RAW 264.7 cells. RAW 264.7 cells $\left(8 \times 10^{4}\right.$ per well) were incubated with 100 ng/ $\mathrm{mL}$ RANKL or both RANKL and SC $(0.6,6$ and $60 \mu \mathrm{g} / \mathrm{mL})$. After 7 days, the supernatant was collected and centrifuged. Total TNF-a concentration was calculated by ELISA. Data are represented as the means \pm S.E.M. of three independent experiments. ${ }^{\#} p<0.05$ compared with non-treated cells. ${ }^{*} p<0.05$ and ${ }^{* *} p<0.01$ compared with only RANKL-treated cells 


\section{Western blotting analysis}

RANKL-induced osteoclast was prepared as mentioned above. On the 7 days after osteoclast induction, cells were lysed with RIPA buffer (Pierce Biotechnology, Rockford, IL, USA) containing protease inhibitors (Roche, Hoffmann, USA). $30 \mu \mathrm{g}$ protein samples were separated in sodium dodecyl sulfate-polyacrylamide gel, and transferred to polyvinylidene fluoride membrane (Bio-Rad, Hercules, CA, USA). Each membrane was incubated with primary $\beta$-actin, TRAF6, NF-кB, Lamin B, ІкB- $\alpha$, p-ІкB- $\alpha$, extracellular signal-regulated kinase (ERK), c-Jun $\mathrm{N}$-terminal kinase (JNK), p38, NFATc1 and c-fos antibodies (Cell Signaling, USA) overnight at $4{ }^{\circ} \mathrm{C}$. Anti-mouse IgG was used as the secondary antibody. Immunoreactivity was detected using an enhanced chemiluminescence detection system. The experiments were carried out 3 times in triplicate measurements.

\section{Statistical analysis}

Significance was determined by one-way analysis of variance (ANOVA) and Dunnett's multiple comparison tests. In all analyses, $P<0.05$ was taken to indicate statistical significance.

\section{Results}

SC suppressed RANKL-induced osteoclast formation

Numerous mature multinucleated TRAP-positive osteoclasts were seen in RANKL-stimulated cells. SC treatment significantly decreased osteoclast differentiation as shown in images by light microscope (Fig. 1a). Also, SC treatment showed the inhibition of RANKL-induced osteoclastogenesis in a dose-dependent manner (17.06, 20.76 and $30.77 \%$, respectively), as determined by measuring the cellular TRAP activity. All concentrations of SC exerted equivalent effects on cell viability. 0.6, 6 and $60 \mu \mathrm{g} / \mathrm{mL} \mathrm{SC}$ treatment had no cytotoxicity to RAW 264.7 cell (Fig. 1b).

\section{SC suppressed RANKL-induced TNF- $a$ secretion}

RANKL increased the concentration of TNF- $\alpha$ in Raw 264.7 cells. Cells treated with SC decreased the secretion of TNF- $\alpha$ compared with cells treated with RANKL alone

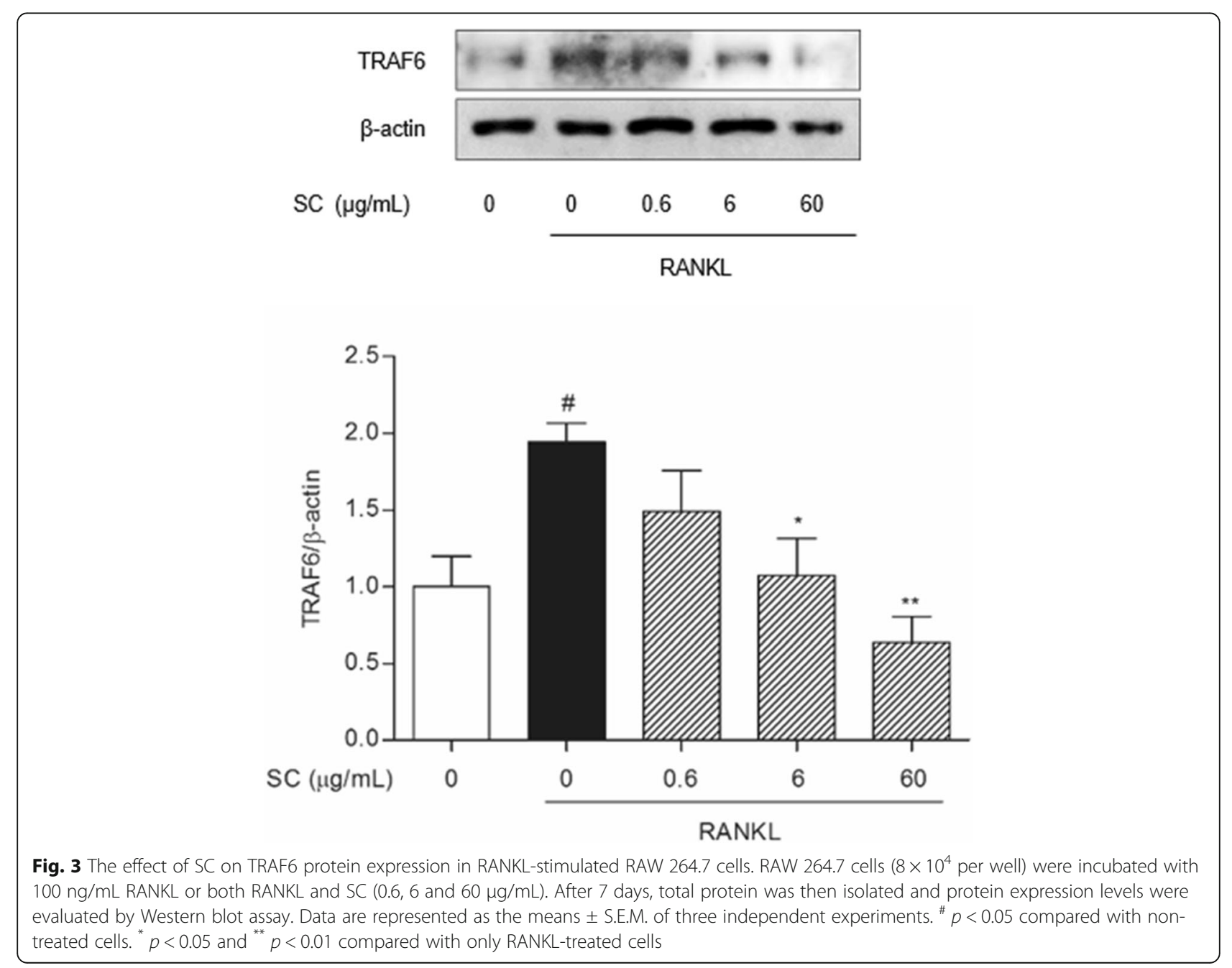


(Fig. 2). Especially, the levels of TNF- $\alpha$ were significantly reduced at the concentrations of 6 and $60 \mu \mathrm{g} / \mathrm{mL} \mathrm{SC}$. The inhibition rates of TNF- $\alpha$ secretion by 6 and $60 \mu \mathrm{g} / \mathrm{mL} \mathrm{SC}$ were 19.3 and $27.6 \%$, respectively.

\section{SC suppressed RANKL-induced TRAF6 expression}

Since TRAF6 is directly recruited by RANK-RANKL complex and related with TNF- $\alpha$ signaling, we confirmed the protein expression of TRAF6 in RANKL-induced Raw 264.7 cells. The protein level of TRAF6 was significantly increased by RANKL treatment. Otherwise, SC at 6 and $60 \mu \mathrm{g} / \mathrm{mL}$ concentrations exhibited a marked inhibitory effect on TRAF6 expression in RANKL-induced Raw 264.7 cells (Fig. 3).

SC suppressed RANKL-induced NF-KB translocation and IKB-a phosphorylation, not MAPKs phosphorylation

RANKL stimulation induced the translocation of NF- $\mathrm{KB}$ into nucleus and the phosphorylation of $\mathrm{I} \kappa \mathrm{B}-\alpha$ in cytoplasm. The expressions of NF- $\mathrm{kB}$ in nuclear protein were reduced by treatment with 6 and $60 \mu \mathrm{g} / \mathrm{mL} \mathrm{SC}$ (Fig. 4a). Similarly, SC co-treated with RANKL inhibited the phosphorylation of IkB- $\alpha$ in cytoplasmic protein compared to cells treated with RANKL alone. In addition, we analyzed the expressions of MAPKs such as ERK, JNK and p38 in RANKL-induced osteoclasts. Compared to non-treated cells, RANKL treatment showed increments of ERK, JNK and p38, respectively. However, SC did not alter RANKL-induced MAPKs expression (Fig. 4b).

\section{SC suppressed RANKL-induced osteoclast-specific transcription factors}

To further define the mechanisms underlying the inhibitory effects of SC on NF-KB activation, the effects of SC on RANKL-induced osteoclast-specific transcription factors such as NFATc1 and c-fos were investigated. As shown in Fig. 5, the expression of NFATc1 was dose-dependently down-regulated in SC-treated cells. In

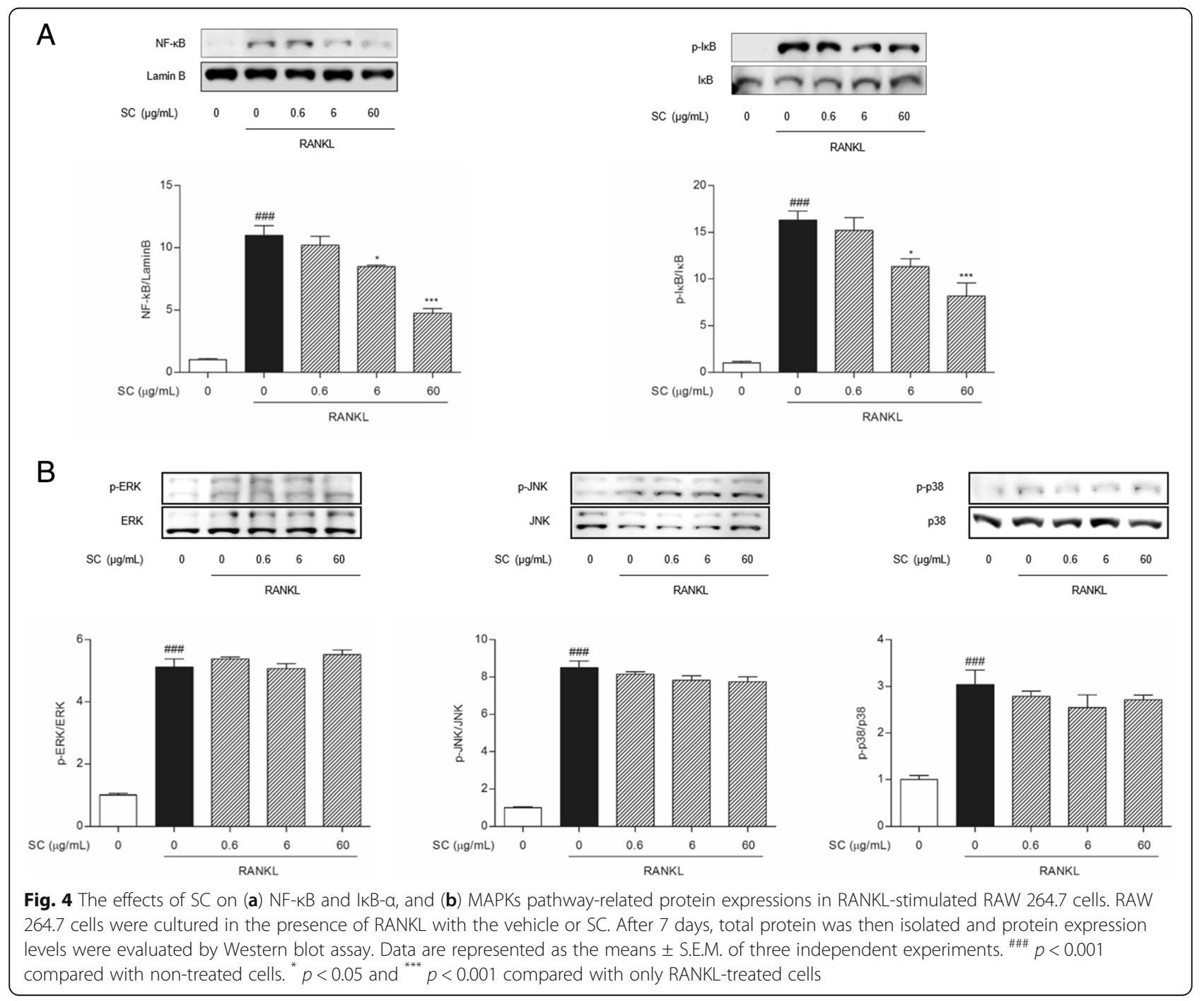




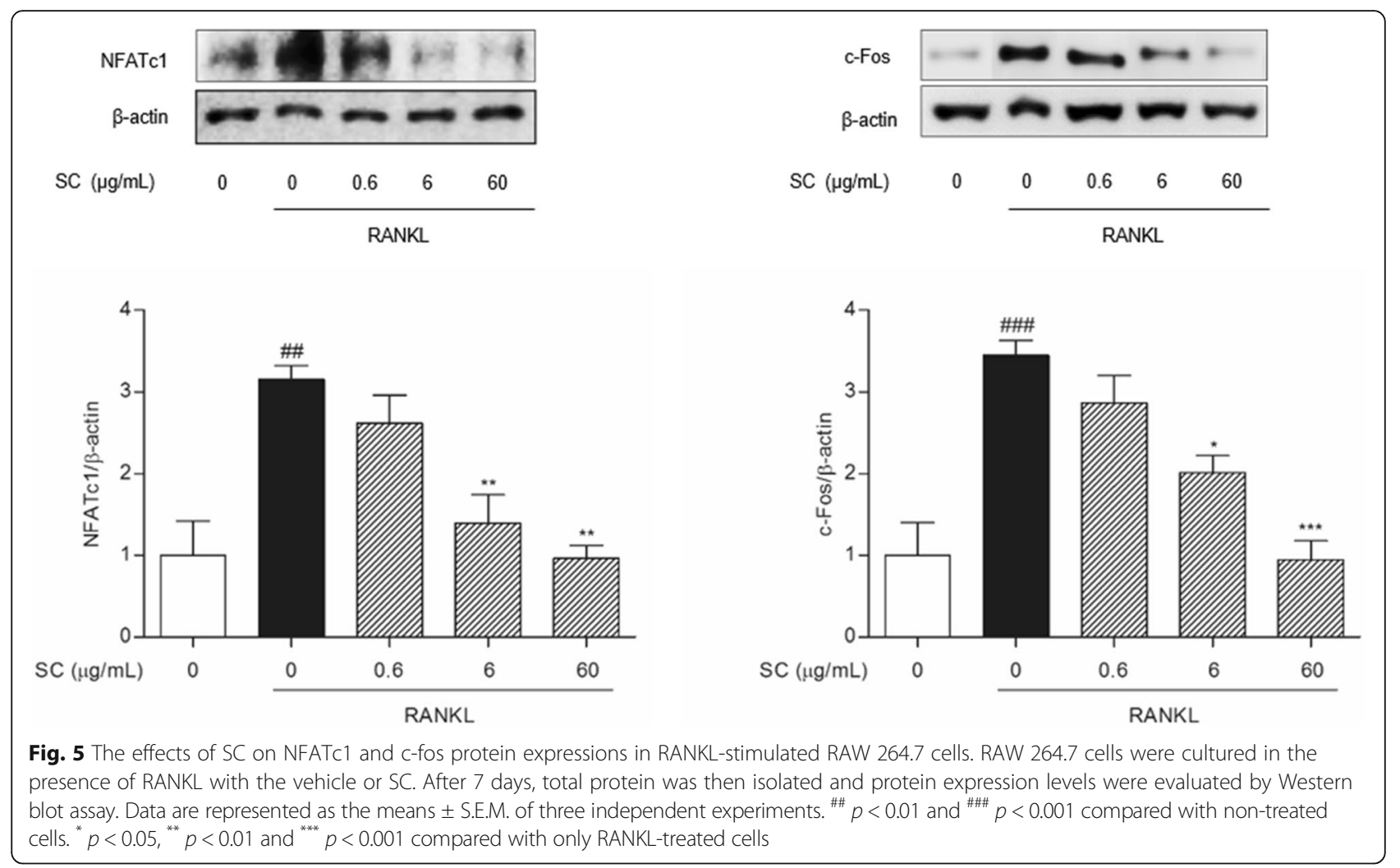

addition, increased c-fos expressions in RANKL-induced osteoclast were significantly suppressed by treatment with 6 and $60 \mu \mathrm{g} / \mathrm{mL} \mathrm{SC}$.

\section{Discussion}

The bone loss is caused by enhanced bone resorption with excessive RANKL signaling [23]. As such, inhibiting the formation of bone-resorbing osteoclasts through suppressing the RANKL signaling or its downstream pathways should be a rational target for the treatment of osteopenic diseases. In the present study, TRAP activities were measured in RANKL-treated Raw 264.7 cells to evaluate the effects of SC on osteoclast differentiation. RANKL induced the development of multinucleated osteoclasts from precursors, and SC treatments exerted preventive effects on the formation of the TRAP-positive osteoclasts without cytotoxicity.

TNF- $\alpha$ mediates RANKL stimulation of osteoclast differentiation by an autocrine mechanism [24]. Recently, it has been reported that TNF- $\alpha$ directly induces the osteoclastogenesis and bone loss. Since both RANKL and TNF- $\alpha$ can activate the same downstream signaling pathways such as NF- $k B$ signal and MAPKs cascades [25], the effect of TNF- $\alpha$ on osteoclasts activation is strongly synergistic with RANKL. Our results showed SC (6 and $60 \mu \mathrm{g} / \mathrm{mL})$ inhibited RANKL-induced TNFo secretion in RAW 264.7 cells. These results indicate that SC acts directly on osteoclast precursors to suppress osteoclast formation.
TRAF6-mediated signals play a key role in RANKL-induced signaling and osteoclast differentiation [26]. Binding of RANKL to RANK recruits TRAF6, forms an intermediate complex, which, in turn, can regulate NF-kB and MAPKs signaling pathways [27]. TRAF6 is presently known to be involved also in TNF- $\alpha$ signaling [28]. In the present study, enhanced TRAF6 expression in RANKL-induced osteoclasts was deceased by $\mathrm{SC}$ treatments (6 and $60 \mu \mathrm{g} / \mathrm{mL}$ ), indicating that SC inhibits osteoclast differentiation via down-regulating the activity of TRAF6-dependent mechanism.

NF- $\kappa \mathrm{B}$ pathway is one of the major intercellular pathways of osteoclasogenesis from precursors directly induced by RANKL-RANK-TRAF6 signaling axis [29]. It is well established that NF- $\mathrm{B}$ pathway in RANKL-induced activation is essential for NFATc1 and c-fos expressions and early osteoclast differentiation [30, 31]. In the present study, SC inhibited the phosphorylation of $\mathrm{I} \kappa \mathrm{B}-\alpha$ and the expressions of NF- $\mathrm{KB}$ in RANKL-induced osteoclasts ( 6 and $60 \mu \mathrm{g} / \mathrm{mL}$ ), which means that $\mathrm{SC}$ could inhibit RANKL-induced activation of NF-kB pathway.

Besides the NF-kB pathway, MAPKs pathways, including ERK, JNK and p38, can be also stimulated by RANKL signaling [27]. Specific inhibitors of MAPKs pathways exhibit the effects of profound suppressions on RANKL-induced osteoclastogenesis from precursor cells [32-34]. Intriguingly, we observe no evidence that 
SC could inhibit RANKL-induced MAPKs pathway during osteoclastogenesis. Our results showed ERK, JNK and p38 phosphorylation was induced by RANKL stimulation, and SC treatments did not alter the increased phosphorylation of RANKL-induced MAPKs. These results seem to indicate that SC treatments inhibited RANKL signaling independently from MAPKs pathways.

NFATc1 and c-fos are specific and indispensable transcription factors for osteoclast formation [35, 36]. These factors are regarded two of the most important transcription factors in osteoclastogenesis, and lack of any of these two components blocks osteoclast formation. NFATc1, as a master regulator downstream of $\mathrm{c}-$ fos, NF- $\mathrm{kB}$ and MAPKs, integrates RANKL signaling in terminal differentiation of osteoclasts [37]. NFATc1 cooperates with c-fos to activate the autoamplification of NFATc1 itself and the transcription of osteoclast-specific genes including calcitonin receptor, TRAP, matrix metallopeptidase 9, and cathepsin K [38-40]. Expression of c-fos is modulated by various signaling pathways such as NF-kB, MAPKs, phosphatidylinositol 3-kinase-Akt and calcium/calmodulin-dependent kinase IV-cAMP response element-binding protein pathways [41]. In this study, SC inhibited the expressions of NFATc1 and c-fos in RANKL-induced osteoclasts. These results suggest that SC could suppress the osteoclastogenesis through osteoclast-specific transcriptional regulation.

\section{Conclusions}

In conclusion, our current data demonstrate that SC attenuates RANKL-induced RAW 264.7 cells differentiation into osteoclasts. Furthermore, the effects of SC were associated with the inhibition of TRAF6 recruitment and inactivation of NF-kB pathway, but not MAPKs pathways, leading to the down-regulations of transcription factors including c-fos and NFATc1. This suggests that S. chinensis could be a promising therapeutic agent for osteopenic disorders.

\section{Additional file}

Additional file 1: HPLC chromatograms of SC. The concentration of schizandrin in SC was $164.372 \mu \mathrm{g} / \mathrm{mL}$ (1.820\%). (TIF $249 \mathrm{~kb}$ )

\section{Abbreviations \\ ERK: Extracellular signal-regulated kinase; JNK: C-Jun N-terminal kinase; MAPKs: Mitogen-activated protein kinase; NFATc1: Nuclear factor of activated T cells; NF-kB: Nuclear factor-kappa B; RANKL: Receptor activator of NF-kB lig- and; SC: Water extract of Schizandra chinensis; TNF: Tumor necrosis factor; TRAF: TNF receptor-associated factors; TRAP: Tartrate resistant acid phosphatase}

\section{Funding}

This work was supported by the Dongguk University Research Fund of 2017. The funding source had no role in the design of the study; collection, analysis, and interpretation of data; and in writing the manuscript.

\section{Availability of data and materials}

The datasets used and analyzed during the current study are available from the corresponding author on reasonable request.

\section{Authors' contributions}

All authors participated in the design, interpretation of the studies and review of the manuscript; EK, HL and MHK contributed to analyzed data, EK drafted the manuscript, and WMY provided supervision of study. All authors read and approved the final manuscript.

\section{Ethics approval and consent to participate}

Not applicable.

\section{Consent for publication}

Not applicable.

\section{Competing interests}

The authors declare that they have no competing interests.

\section{Publisher's Note}

Springer Nature remains neutral with regard to jurisdictional claims in published maps and institutional affiliations.

\section{Author details}

${ }^{1}$ College of Korean Medicine, Dongguk University, Gyeongju, Republic of Korea. ${ }^{2}$ Department of Convergence Korean Medical Science, College of Korean Medicine, Kyung Hee University, 26 Kyungheedae-ro,

Dongdaemun-gu, Seoul 02447, Republic of Korea.

Received: 10 October 2017 Accepted: 20 September 2018

Published online: 01 October 2018

\section{References}

1. Boyle WJ, Simonet WS, Lacey DL. Osteoclast differentiation and activation. Nature. 2003;423(6937):337-42.

2. Gruber H, Ivey J, Thompson E, Chesnut C 3rd, Baylink D. Osteoblast and osteoclast cell number and cell activity in postmenopausal osteoporosis. Miner Electrol Metab. 1985;12(4):246-54.

3. Roato I, Grano M, Brunetti G, Colucci S, Mussa A, Bertetto O, Ferracini R. Mechanisms of spontaneous osteoclastogenesis in cancer with bone involvement. FASEB J. 2005;19(2):228-30.

4. Sakellari D, Menti S, Konstantinidis A. Free soluble receptor activator of nuclear factor-kb ligand in gingival crevicular fluid correlates with distinct pathogens in periodontitis patients. J Clin Periodontol. 2008;35(11):938-43.

5. Neale S, Smith R, Wass J, Athanasou N. Osteoclast differentiation from circulating mononuclear precursors in Paget's disease is hypersensitive to 1, 25-dihydroxyvitamin D 3 and RANKL. Bone. 2000:27(3):409-16.

6. Hirayama T, Danks L, Sabokbar A, Athanasou N. Osteoclast formation and activity in the pathogenesis of osteoporosis in rheumatoid arthritis. Rheumatology. 2002;41(11):1232-9.

7. Arai F, Miyamoto T, Ohneda O, Inada T, Sudo T, Brasel K, Miyata T, Anderson DM, Suda T. Commitment and differentiation of osteoclast precursor cells by the sequential expression of c-Fms and receptor activator of nuclear factor KB (RANK) receptors. J Exp Med. 1999;190(12):1741-54.

8. Karsenty $G$, Wagner EF. Reaching a genetic and molecular understanding of skeletal development. Dev Cell. 2002;2(4):389-406.

9. Wong BR, Josien R, Lee SY, Vologodskaia M, Steinman RM, Choi Y. The TRAF family of signal transducers mediates NF-KB activation by the TRANCE receptor. J Biol Chem. 1998;273(43):28355-9.

10. Suda T, Nakamura I, Jimi E, Takahashi N. Regulation of osteoclast function. J Bone Miner Res. 1997;12(6):869-79.

11. Lacey D, Timms E, Tan H-L, Kelley M, Dunstan C, Burgess T, Elliott R, Colombero A, Elliott G, Scully S. Osteoprotegerin ligand is a cytokine that regulates osteoclast differentiation and activation. Cell. 1998;93(2):165-76.

12. Aoki K, Saito H, Itzstein C, Ishiguro M, Shibata T, Blanque R, Mian AH, Takahashi M, Suzuki Y, Yoshimatsu M. A TNF receptor loop peptide mimic blocks RANK ligand-induced signaling, bone resorption, and bone loss. J Clin Invest. 2006;116(6):1525-34.

13. Chae H-S, Kang O-H, Oh Y-C, Choi J-G, Keum J-H, Kim S-B, Kim Y-S, Mun SH, Shin D-W, Han S-H. Gomisin N has anti-allergic effect and inhibits 
inflammatory cytokine expression in mouse bone marrow-derived mast cells. Immunopharm Immunot. 2011;33(4):709-13.

14. Szopa A, Ekiert R, Ekiert H. Current knowledge of Schisandra chinensis (Turcz.) Baill. (Chinese magnolia vine) as a medicinal plant species: a review on the bioactive components, pharmacological properties, analytical and biotechnological studies. Phytochem Rev: Pr Phyt Soc. 2017;16(2):195-218.

15. Nakajima K, Taguchi H, Ikeya Y, Endo T, Yosioka I. Constituents of Schizandra chinensis Baill. XIII. Quantitative analysis of lignans in the fruits of Schizandra chinensis Baill. By high performance liquid chromatography. Yakugaku Zasshi. 1983;103(7):743.

16. Caichompoo W, Zhang QY, Hou TT, Gao HJ, Qin LP, Zhou XJ. Optimization of extraction and purification of active fractions from Schisandra chinensis (Turcz.) and its osteoblastic proliferation stimulating activity. Phytother Res. 2009;23(2):289-92.

17. Kim MH, Choi YY, Han JM, H-S L, Hong SB, S-G L, Yang WM. Ameliorative effects of Schizandra chinensis on osteoporosis via activation of estrogen receptor (ER)-a/- $\beta$. Food Funct. 2014;5(7):1594-601.

18. Kang Y-S, Han M-H, Hong S-H, Park C, Hwang H-J, Kim BW, Kyoung KH, Young Whan Choi CMK, Choi YH. Anti-inflammatory effects of Schisandra chinensis (Turcz.) Baill fruit through the inactivation of nuclear factor-kB and mitogen-activated protein kinases signaling pathways in lipopolysaccharidestimulated murine macrophages. J Cancer Prev. 2014;19(4):279-87.

19. Guo LY, Hung TM, Bae KH, Shin EM, Zhou HY, Hong YN, Kang SS, Kim HP, Kim YS. Anti-inflammatory effects of schisandrin isolated from the fruit of Schisandra chinensis Baill. Eur J Pharmacol. 2008:591(1):293-9.

20. Oh S-Y, Kim YH, Bae DS, Um BH, Pan C-H, Kim CY, Lee HJ, Lee JK. Antiinflammatory effects of gomisin $\mathrm{N}$, gomisin J, and schisandrin C isolated from the fruit of Schisandra chinensis. Biosci Biotechnol Biochem. 2010; 74(2):285-91.

21. He Y, Zhang Q, Shen Y, Chen X, Zhou F, Peng D. Schisantherin a suppresses osteoclast formation and wear particle-induced osteolysis via modulating RANKL signaling pathways. Biochem Bioph Res Co. 2014;449(3):344-50.

22. Lu Y, Chen D-F. Analysis of Schisandra chinensis and Schisandra sphenanthera. J Chromatogr. 2009:1216(11):1980-90.

23. Teitelbaum SL. Bone resorption by osteoclasts. Science. 2000;289(5484): 1504-8.

24. Zou W, Hakim I, Tschoep K, Endres S, Bar-Shavit Z. Tumor necrosis factor-a mediates RANK ligand stimulation of osteoclast differentiation by an autocrine mechanism. J Cell Biochem. 2001;83(1):70-83.

25. Yamashita T, Yao Z, Li F, Zhang Q, Badell IR, Schwarz EM, Takeshita S, Wagner EF, Noda M, Matsuo K. NF-KB p50 and p52 regulate receptor activator of NF-KB ligand (RANKL) and tumor necrosis factor-induced osteoclast precursor differentiation by activating c-Fos and NFATc1. J Biol Chem. 2007;282(25):18245-53.

26. Mizukami J, Takaesu G, Akatsuka H, Sakurai H, Ninomiya-Tsuji J, Matsumoto K, Sakurai N. Receptor activator of NF-KB ligand (RANKL) activates TAK1 mitogen-activated protein kinase kinase kinase through a signaling complex containing RANK, TAB2, and TRAF6. Mol Cell Biol. 2002;22(4):992-1000.

27. Leibbrandt A, Penninger JM. RANK/RANKL: regulators of immune responses and bone physiology. Ann N Y Acad Sci. 2008;1 143(1):123-50.

28. Kaji K, Katogi R, Azuma Y, Naito A, Inoue Jl, Kudo A. Tumor necrosis factor a-induced Osteoclastogenesis requires tumor necrosis factor receptorassociated factor 6. J Bone Miner Res. 2001;16(9):1593-9.

29. Franzoso G, Carlson L, Xing L, Poljak L, Shores EW, Brown KD, Leonardi A, Tran T, Boyce BF, Siebenlist U. Requirement for NF-KB in osteoclast and Bcell development. Genes Dev. 1997;11(24):3482-96.

30. Lee $\mathrm{ZH}$, Kim H-H. Signal transduction by receptor activator of nuclear factor kappa B in osteoclasts. Biochem Bioph Res Co. 2003;305(2):211-4.

31. Bruzzaniti A, Baron R. Molecular regulation of osteoclast activity. Rev Endocr Metab Disord. 2006;7(1-2):123-39.

32. Matsumoto M, Sudo T, Saito T, Osada H, Tsujimoto M. Involvement of p38 mitogen-activated protein kinase signaling pathway in osteoclastogenesis mediated by receptor activator of NF-kB ligand (RANKL). J Biol Chem. 2000; 275(40):31155-61.

33. Lee J-H, Jin H, Shim H-E, Kim H-N, Ha H, Lee ZH. Epigallocatechin-3-gallate inhibits osteoclastogenesis by down-regulating c-Fos expression and suppressing the nuclear factor-KB signal. Mol Pharmacol. 2010;77(1):17-25.

34. David J-P, Sabapathy K, Hoffmann O, Idarraga MH, Wagner EF. JNK modulates osteoclastogenesis through both c-Jun phosphorylationdependent and-independent mechanisms. J Cell Sci. 2002;115(22):4317-25.
35. Grigoriadis AE, Wang Z-Q, Cecchini MG, Hofstetter W, Felix R, Fleisch HA, Wagner EF. C-Fos: a key regulator of osteoclast-macrophage lineage determination and bone remodeling. Science. 1994;266(5184):443-9.

36. Takayanagi H, Kim S, Koga T, Nishina H, Isshiki M, Yoshida H, Saiura A, Isobe $M$, Yokochi T, J-I I. Induction and activation of the transcription factor NFATC1 (NFAT2) integrate RANKL signaling in terminal differentiation of osteoclasts. Dev Cell. 2002;3(6):889-901.

37. Kim JH, Kim N. Regulation of NFATC1 in osteoclast differentiation. J Bone Metab. 2014;21(4):233-41.

38. Asagiri M, Sato K, Usami T, Ochi S, Nishina H, Yoshida H, Morita I, Wagner EF, Mak TW, Serfling E. Autoamplification of NFATc1 expression determines its essential role in bone homeostasis. J Exp Med. 2005;202(9):1261-9.

39. Takayanagi H. Osteoimmunology: shared mechanisms and crosstalk between the immune and bone systems. Nat Rev Immunol. 2007;7(4): 292-304.

40. Teitelbaum SL, Ross FP. Genetic regulation of osteoclast development and function. Nat Rev Genet. 2003;4(8):638-49.

41. Sato K, Suematsu A, Nakashima T, Takemoto-Kimura S, Aoki K, Morishita Y, Asahara H, Ohya K, Yamaguchi A, Takai T. Regulation of osteoclast differentiation and function by the CaMK-CREB pathway. Nat Med. 2006;12(12):1410-6.

\section{Ready to submit your research? Choose BMC and benefit from:}

- fast, convenient online submission

- thorough peer review by experienced researchers in your field

- rapid publication on acceptance

- support for research data, including large and complex data types

- gold Open Access which fosters wider collaboration and increased citations

- maximum visibility for your research: over $100 \mathrm{M}$ website views per year

At BMC, research is always in progress.

Learn more biomedcentral.com/submissions 